\title{
QUEEN'S
UNIVERSITY
BELFAST
}

\section{Plasma antioxidant status in patients with Alzheimer's disease and cognitively intact elderly: A meta-analysis of case-control studies}

Mullan, K., Cardwell, C. R., McGuinness, B., Woodside, J. V., \& McKay, G. J. (2018). Plasma antioxidant status in patients with Alzheimer's disease and cognitively intact elderly: A meta-analysis of case-control studies. Journal of Alzheimer's Disease, 62(1), 305-317. https://doi.org/10.3233/JAD-170758

Published in:

Journal of Alzheimer's Disease

Document Version:

Peer reviewed version

Queen's University Belfast - Research Portal:

Link to publication record in Queen's University Belfast Research Portal

Publisher rights

(C) 2018 IOS Pres.

This work is made available online in accordance with the publisher's policies. Please refer to any applicable terms of use of the publisher.

\section{General rights}

Copyright for the publications made accessible via the Queen's University Belfast Research Portal is retained by the author(s) and / or other copyright owners and it is a condition of accessing these publications that users recognise and abide by the legal requirements associated with these rights.

Take down policy

The Research Portal is Queen's institutional repository that provides access to Queen's research output. Every effort has been made to ensure that content in the Research Portal does not infringe any person's rights, or applicable UK laws. If you discover content in the Research Portal that you believe breaches copyright or violates any law, please contact openaccess@qub.ac.uk. 


\section{Plasma antioxidant status in patients with}

\section{Alzheimer's disease and cognitively intact elderly: A meta-analysis of case-control studies}

Kathryn Mullan ${ }^{\mathrm{a}}$, Chris R. Cardwell ${ }^{\mathrm{a}}$, Bernadette McGuinness ${ }^{\mathrm{a}}$, Jayne V. Woodside ${ }^{\mathrm{a}}$, Gareth J. $\operatorname{McKay}^{\mathrm{a} *}$

${ }^{\mathrm{a} C e n t r e ~ f o r ~ P u b l i c ~ H e a l t h, ~ Q u e e n ' s ~ U n i v e r s i t y ~ B e l f a s t, ~ B e l f a s t, ~ U K ~}$

*Corresponding author:

Dr Gareth McKay

Centre for Public Health

Queen's University Belfast

Institute of Clinical Science B

Royal Victoria Hospital

Belfast

BT12 6BA

Telephone: 00442890978958

Email: g.j.mckay@qub.ac.uk

\section{ABSTRACT}

Serum antioxidants may afford neuroprotection against Alzheimer's disease (AD) via correction of the pro-oxidative imbalance but findings reported have been inconsistent. We compared the 
pooled mean difference in serum levels of ten dietary antioxidants between patients with $\mathrm{AD}$ and cognitively intact controls from 52 studies in meta-analyses using random-effects models. Patients with $\mathrm{AD}$ had significantly lower plasma levels of $\alpha$-carotene, $\beta$-carotene, lycopene, lutein, vitamin $\mathrm{A}, \mathrm{C}$ and $\mathrm{E}$, and uric acid. No significant difference was observed for plasma levels of $\beta-$ cryptoxanthin and zeaxanthin. Considerable heterogeneity was detected across studies. The lower serum levels of dietary antioxidants from the carotene and vitamin subclasses observed in individuals with $\mathrm{AD}$ suggest reduced systemic availability of these subclasses in this prevalent form of dementia. To our knowledge, these are the first meta-analyses to demonstrate lower serum lycopene and to evaluate $\beta$-cryptoxanthin, lutein and zeaxanthin levels in $\mathrm{AD}$. In light of the significant heterogeneity detected across studies, caution should be exercised in the interpretation of the data and therapeutic intervention approaches considered through supplementation measures. Our data may better inform interventions to improve antioxidant status in a condition of major public health importance.

Keywords: $\quad$ Alpha-carotene; Beta-carotene; Beta-cryptoxanthin; Lutein; Lycopene; Uric Acid; Vitamin A; Vitamin C; Vitamin E; Zeaxanthin

Abbreviations: AD, Alzheimer's disease; UA, uric acid; OS, oxidative stress; ROS, reactive oxygen species; FVs, fruit and vegetables; $\mathrm{MCI}$, mild cognitive impairment; PMD, pooled mean difference; $\mathrm{CI}$, confidence interval; TAC, total antioxidant capacity. 


\section{INTRODUCTION}

An estimated 46 million people are affected worldwide by dementia, with 7.7 million new cases reported each year and numbers predicted to increase significantly through ageing populations [1]. Alzheimer's disease (AD) is the most common dementia subtype characterized by brain atrophy and accumulation of amyloid-plaques and neurofibrillary tangles throughout the cortex [2]. Multiple neuropathologic processes have been implicated in the onset of cognitive decline leading to this devastating disease, a process influenced by multiple modifiable and non-modifiable risk factors $[1,3]$.

Oxidative stress (OS) is a pathophysiological imbalance in the production of reactive oxygen species (ROS) and antioxidants, in favor of the former which has been implicated early in the dementia disease etiology [4]. Cerebral tissue is especially vulnerable to ROS due to its high content of polyunsaturated fatty acids and relatively low levels of antioxidants to cope with its high metabolic activity. Oxidative damage results from this antioxidant deficit leading to neuronal cell death and subsequent depletion in antioxidant defenses in the brain and circulation of patients with AD [4-5]. The body produces some endogenous antioxidants, however less potent dietary antioxidants are required for additional protective support to scavenge active radicals [6].

The main classes of exogenous antioxidants include polyphenols, vitamins and carotenoids. Major sources of polyphenols, or more specifically flavonoids, include chocolate, wine and green tea. Vitamin $\mathrm{E}$, one of the most promising vitamins in $\mathrm{AD}$ research can be found in whole grains such as cereals and high quality vegetable oils. Fruit and vegetables (FVs) are major dietary sources of carotenoids, comprising of two subclasses, namely xanthophylls and carotenes. Furthermore, adequate consumption of FVs as well as nutritional supplementation has shown to be effective in 
potentiating plasma antioxidant levels [7]. Individuals with AD have been identified as a highrisk group for having poor diets lacking in FVs with FV intake previously reported to be associated with cognitive function [8]. Nutritional influences in AD have the potential to bear major public health significance therefore we have focused on consequential serum antioxidant status rather than dietary intake as a more objective measure.

There has been significant interest in observational studies assessing the association between serum levels of antioxidants and $\mathrm{AD}$ given their potential neuroprotective effect. Despite numerous epidemiological studies over the past three decades, no definitive evidence is available. This may be partly due to the major limitation of retrospective case control studies whereby the degree of oxidative damage and subsequent cognitive impairment is often not assessed until the point of AD diagnosis in the cases which is believed to predate many of the clinical signs associated with the disease. This will not manifest to the same extent in controls and, in the presence of such deferential misclassification, estimates of the association between serum antioxidant status and $\mathrm{AD}$ will be biased upwards making the results of retrospective studies difficult to interpret. This problem has been overcome by the addition of more recent case control studies nested within prospective cohorts where blood samples are collected closer to the time of onset of cognitive decline.

Two previous meta-analyses, the former including 80 studies published up to March 2012 and a more recent publication including 65 studies published up to August 2012, both reported negative associations between serum levels of antioxidants and $\mathrm{AD}$ although deemed the quality of evidence to be low $[9,10]$. Furthermore, randomized controlled trials (RCTs) evaluating antioxidant supplementation have failed to substantiate the findings from observational studies through 
improved cognitive function measures $[11,12]$. Further investigation of the epidemiological data available is necessary to improve our understanding of the complexity of these associations, given the contrast in previous findings.

Both publications combined largely retrospective studies on several dietary antioxidants within the various subclasses. Since then, at least 8 new case-control studies have confirmed or refuted an association between serum antioxidant status and AD. We therefore conducted a large-scale analysis using data obtained from prospective and retrospective studies from 1991 to 2016 to evaluate the magnitude of this relationship more precisely and assess the grouped mean difference in relevant subgroups, where applicable.

As such, we have compared the plasma antioxidant status of individuals with AD and cognitively intact controls from 52 published studies using random effects meta-analysis of ten antioxidants. We report on antioxidant vitamins (serum vitamins A, C and E) and the serum carotenoids (lutein, zeaxanthin, $b$-cryptoxanthin of the xanthophyll subclass and $\alpha$-carotene, $\beta$-carotene and lycopene of the carotene subclass, along with uric acid).

\section{MATERIAL AND METHODS}

We undertook a systematic review and meta-analysis according to the guidelines of the Preferred Reporting Items for Systematic Reviews and Meta-Analysis (PRISMA) statement [13].

Literature search strategy and selection criteria

Literature published in English from 1970 to September $30^{\text {th }} 2016$, was systematically screened by two reviewers (KM and GMK) in PubMed, Embase, SCOPUS and ISI Web of Science electronic databases using the following search terms in the title, abstract or descriptors: 
[(Alzheimer OR dementia) AND (serum OR plasma OR blood) AND (carotene OR carotenoids OR cryptoxanthin OR lutein OR xanthophyll OR lycopene OR uric acid OR urate OR retinol OR retinoic OR vitamin A OR ascorbate OR ascorbic acid OR vitamin C OR tocopherol OR vitamin E OR zeaxanthin)].The following inclusion criteria were used: (1) contained an AD population defined using a clearly stated AD diagnostic criteria; (2) mentioned the use of a cognitively intact elderly control group; (3) reported summary statistic values of plasma antioxidant levels for AD cases and controls; (4) estimated plasma antioxidants levels using established analysis methods, (5) stated the number of AD cases and controls, and (6) stated the mean age or age range of case and control groups. The diagnosis of $\mathrm{AD}$ was not limited to any specific diagnostic criteria or method of plasma/serum antioxidant measurement. The following publications were excluded: those concerning other cognitive disorders (e.g. mild cognitive impairment [MCI], frontotemporal dementia, vascular dementia, or combination of $\mathrm{AD}$ and dementia subtypes), those where the control group was not cognitively intact and those that included subjects using vitamin supplements as an adjuvant treatment to slow AD progression.

\section{Data extraction}

Two reviewers (KM and GMK) evaluated the eligibility of potentially relevant documents independently, and any discrepancies were discussed with a third reviewer (CC) until a clear consensus was reached. On closer analysis of the retrieved studies, it became apparent that some publications contained data derived from the same study population. Only the study with the most complete set of data was included. Furthermore, it was also observed that some of the studies had incomplete data fields and, where direct correspondence with the authors for additional data was 
unsuccessful, these studies were excluded. The aforementioned limitations excluded a further nine studies.

For each antioxidant, the following study characteristics were extracted from publications using a predesigned form (see supplementary material): (1) name of first author, (2) publication year, (3) matching factors, (4) mean age or age range of cases and controls, (5) method of plasma antioxidant level measurement, (6) number of AD cases and cognitively intact controls, and (7) plasma antioxidant values.

The plasma antioxidant data was compiled and presented as summary statistics (N, mean and standard deviation [SD]). For studies reporting non-parametric summary data, normal distribution was assumed to allow conversion to parametric summary statistics using established methods. Several studies reported on multiple groups of AD patients subdivided by disease severity, stage or APOE genotype; in these circumstances, the mean of all subgroup summary data was calculated to obtain an average summary statistic for cases in the study. Further methodological details regarding data extraction and manipulation are provided in the supplemental material.

Data synthesis and meta-analysis

Meta-analysis was performed when four or more publications were retrieved for a specific antioxidant. Identical measurement units were required to analyse results by pooled mean difference (PMD) for each study. To enable cross study comparison, plasma antioxidant values were expressed in Standard International System of Units of micromoles per liter ( $\mu$ moles/liter). Accordingly, a conversion was performed for those studies reporting data in the conventional units using a value specific to the antioxidant under investigation (see supplementary data). To compare the plasma/serum levels of individuals with $\mathrm{AD}$ with cognitively normal controls, all reported 
antioxidant values were integrated and summarized for the pooled population expressed as PMD with 95\% confidence intervals (95\% CI) using meta-analysis (regression) methods, according to the PRISMA statement [13]. These estimates were combined using random-effects meta-analysis models implemented by Review Manager (RevMan) [Computer program], Version 5.3 [14]. Publication bias was analyzed for each outcome through visual analysis of funnel plots and the $\mathrm{I}^{2}$ statistic to detect the presence of heterogeneity across included studies and quantify the percentage of variability attributed to between-study differences. Heterogeneity among studies was also evaluated using the Chi-square test based on Cochran's Q statistic. In addition, sensitivity analyses were conducted by omitting one study per iteration and recalculating to determine if an individual study significantly affected the pooled estimate. Further details on the search strategy, data extraction, analysis techniques, tests of heterogeneity and lists of excluded publications is provided (supplementary material).

\section{RESULTS}

A total of 2,508 articles were identified, 2,489 by initial keyword search and an additional 20 from published reference lists. Duplicate articles $(1,754)$ were removed and the title and abstract of the remaining 755 publications were screened and evaluated according to predefined inclusion and exclusion criteria with no restriction based on year (Figure 1). Included were case-control studies with human subjects that may have contained plasma antioxidant measurements of individuals with $\mathrm{AD}$ and cognitively normal controls, even if not explicit in the abstract. Excluded were conference papers, reviews, abstracts, and those not written in English ( $\mathrm{n}=653)$. Studies with non- 
human subjects were also excluded. This left 102 full text articles for consideration with 52 retained for inclusion within the systematic review.

Included publications reported at least one plasma antioxidant level providing information on the following antioxidants; $\alpha$-carotene (8 studies) [15-22], $\beta$-carotene (13 studies) [15-22, 24-28], lycopene (7 studies) $[15,18-20,22,27,28], \beta$-cryptoxanthin (4 studies) $[18-20,22]$, lutein $(5$ studies) [18-20, 22-23], zeaxanthin (5 studies) [18-20, 22-23], vitamin A (15 studies) [15, 16, 1821, 24, 26, 29-35], vitamin C (16 studies) [15, 17-21, 25, 27-29, 31, 35-39] vitamin E (31 studies) $[15,17-20,24-35,38-51]$ and uric acid (21 studies) $[15,18-20,33,42-43,49,52-63]$. The summary results for each antioxidant are provided in Table 1.

Antioxidants were considered within their dietary classes, namely carotenoids and vitamins. The carotenoid class can be further divided into two subclasses based on polarity: carotenes and their oxygenated derivatives, xanthophylls. The carotene subclass consists of $\alpha$-carotene, $\beta$-carotene and lycopene; xanthophylls include $\beta$-cryptoxanthin, lutein and zeaxanthin and vitamins encompass vitamin $\mathrm{A}$, vitamin $\mathrm{C}$ and vitamin $\mathrm{E}$. Although regarded as an endogenous antioxidant, uric acid (UA) was also included in the meta-analysis as a proxy for total antioxidant capacity (TAC) given its significant role in free radical scavenging and providing $60-80 \%$ of TAC in plasma [64]. Results identified significantly lower plasma $\alpha$-carotene, $\beta$-carotene, lycopene, uric acid, vitamins $\mathrm{A}, \mathrm{C}$ and $\mathrm{E}$ in individuals with $\mathrm{AD}$ compared to cognitively intact controls.

\section{Carotenes}

Significantly lower plasma levels were observed between AD cases and cognitively intact controls for all three members of this subclass on pooled analysis of each antioxidant. Alpha-carotene 
There was variation in the reported associations observed across all eight studies containing 327 AD patients and 267 cognitively intact controls with four describing lower plasma $\alpha$-carotene levels in AD patients compared to non-demented controls [17-20]. No significant difference was reported across four additional studies $[15,16,21-22]$. On pooled analysis, plasma $\alpha$-carotene levels were $0.03 \mu$ moles/ $/$ lower in cases versus controls (95\% CI: $-0.05,-0.01 ; P=0.002$; Table 1, Figure 2a). Significant heterogeneity was observed between studies $\left(\mathrm{I}^{2}=79 \%, P<0.00001\right)$, although sensitivity analysis through the omission of one study per iteration, showed no significant change in the PMD.

Beta-carotene

Five studies reported lower plasma $\beta$-carotene levels in $\mathrm{AD}$ patients $[16,18,24,26-27]$ whereas eight found no significant difference between cases and controls [15, 17, 19-22, 25, 28]. The PMD for the thirteen studies with $701 \mathrm{AD}$ patients and 633 cognitively intact controls using a randomeffects model showed beta-carotene levels were $0.11 \mu$ moles/l lower in cases versus controls ( $95 \%$ CI: $-0.17,-0.04 ; P=0.0008$; Table 1 , Figure $2 b)$. Significant heterogeneity was observed $\left(\mathrm{I}^{2}=86 \%\right.$, $P<0.00001)$, although in a sensitivity analysis, no single study was found responsible.

Lycopene

Pooled meta-analysis of seven studies with 424 AD patients and 319 cognitively intact controls showed that individuals with AD had $0.15 \mu$ moles/l lower levels of lycopene (95\% CI: -0.27, $0.02 ; P=0.02$; Table 1 , Figure $2 \mathrm{c}$ ) than cognitively intact controls. Individually, two studies reported lower plasma lycopene levels in AD cases [18-19] and five reported no difference [15, $20,22,27,28]$. Significant heterogeneity was observed among studies $\left(I^{2}=95 \%, P<0.00001\right)$. In 
a sensitivity analysis, the PMD was no longer significant following omission of studies by Mecocci et al [18] and Polidori et al. [19].

Xanthophylls

Significantly lower lutein plasma levels were observed between AD cases and cognitively intact controls on pooled analysis The differences observed in the plasma levels of beta-cryptoxanthin and zeaxanthin did not reach significance on pooled analysis of each antioxidant.

Beta-cryptoxanthin

The levels of $\beta$-cryptoxanthin in $\mathrm{AD}$ subjects was analysed in four studies with two reporting a significant reduction in those with $\mathrm{AD}[18,20]$ and two showing no significant difference $[19,22]$. Cumulatively with 174 individuals with $\mathrm{AD}$ and 145 cognitively intact controls, there was no significant difference in beta-cryptoxanthin (PMD: $-0.13 \mu$ moles/1, 95\% CI: $-0.28,0.01 ; P=0.08$; Table 1, Figure 3a). Significant heterogeneity was observed across studies $\left(\mathrm{I}^{2}=93 \%, P<0.00001\right)$. In a sensitivity analysis, a significant difference was detected following omission of the study by Wang et al (PMD: -0.19 $\mu$ moles/1; (95\% CI: -0.35, -0.03; $P=0.02)$ [22].

Lutein

Plasma lutein from AD subjects was evaluated in five studies with 210 AD patients and 178 cognitively intact controls, three reported a significant reduction in AD patients [19-20, 23] while two showed no significant difference $[18,22]$. Collectively, a significant difference in plasma lutein levels in $\mathrm{AD}$ was found. (PMD -0.13, 95\% CI: -0.23, $-0.03, P=0.01$; Table 1, Figure 3b). Heterogeneity within the five studies was high, $\left(\mathrm{I}^{2}=88 \%, P<0.0001\right)$. Again, omission of the study by Wang et al. in the sensitivity analysis highlighted a significant lower level of plasma lutein in $\mathrm{AD}$ patients [22]. 
Zeaxanthin

Of the five studies evaluating plasma zeaxanthin levels in AD with 210 AD patients and 178 cognitively intact controls,; three reported significantly lower levels amongst AD subjects compared with controls $[18,20,23]$. In the other two studies [19, 22], no significant difference was found in plasma zeaxanthin levels between the two groups. Collectively there was no significant difference in plasma zeaxanthin levels (PMD $-0.03 \mu$ moles $/ 1,95 \%$ CI: $-0.07,0.00, P=$ 0.06; Table 1, Figure 3c). Significant heterogeneity was detected, $\left(I^{2}=94 \%, P<0.0001\right)$ and again omission of the study by Wang et al. identified a significantly lower level of serum zeaxanthin in those with $\mathrm{AD}[22]$.

Vitamins

AD patients showed significantly lower levels of all members of this subclass when compared with controls $(P<0.00001)$.

Vitamin A

Fifteen studies were identified that measured plasma vitamin A levels in AD with $752 \mathrm{AD}$ patients and 1,104 cognitively intact controls; nine reporting significantly lower levels in AD [15-16, 18, 20, 24-25, 29-30, 35] and six reporting no significant difference between AD patients and cognitively intact controls [19, 21, 31-34]. Pooled analysis suggested lower vitamin A levels in AD with PMD $-0.26 \mu$ moles/l (95\% CI: $-0.33,-0.18, P<0.00001$; Table 1, Figure 4a). Sensitivity analysis failed to identify a specific publication to account for the considerable heterogeneity detected. $\left(\mathrm{I}^{2}=88 \%, \mathrm{p}<0.0001\right)$.

Vitamin C 
Pooled analysis of the sixteen studies with 623 AD patients and 491 cognitively intact controls revealed lower plasma levels of Vitamin $\mathrm{C}$ in those with $\mathrm{AD}$ compared to non-demented controls (PMD -12.58 $\mu$ moles/1, 95\% Cl -17.73, -7.43, $P<0.00001$; Table 1, Figure 4b). Individually, nine studies reported significantly lower levels in patients with $\mathrm{AD}[15,18-20,27,29,31,35,38]$ while the remaining seven studies found no significant difference between groups [17, 21, 25, 28, 36-37, 39]. Significant heterogeneity was observed across studies $\left(I^{2}=95 \%, P<0.00001\right)$ but sensitivity analysis failed to attribute this to a single study.

Vitamin E

Vitamin $\mathrm{E}$ was the most frequently investigated dietary antioxidant with 31 studies included with 1,554 AD patients and 1,872 cognitively intact controls. Fifteen studies reported no significant difference between groups [17, 27, 29, 32, 34, 39-46, 48, 49], while sixteen studies found vitamin E to be lower in the plasma of AD patients than cognitively intact controls [15, 18-20, 24-26, 28, 30-31, 33, 35, 38, 47, 50-51]. Pooled meta-analysis showed lower plasma vitamin E levels (5.26 $\mu$ moles/l) in AD patients compared to cognitively intact controls $(95 \% \mathrm{Cl}-6.64,-3.89, P<$ 0.00001; Table 1, Figure 4c). Significant heterogeneity was observed between studies with sensitivity analysis unable to attribute this to any specific publication.

Uric Acid

Twenty-one studies included uric acid measurements, with 1,110 AD patients and 2,384 cognitively intact controls. Results were conflicting; twelve studies described lower plasma uric acid levels in $\mathrm{AD}[20,35,38,43,52,54-55,57-58,60,62-63]$, one study reported the opposite [15] and eight described no significant difference [19, 33, 42, 49, 53, 56, 59, 61]. In aggregation, this data suggested plasma uric acid was significantly lower in AD compared to controls with a 
PMD -27.37 $\mu$ moles/l (95\% CI: $-49.75,-5.00, P=0.02$; Table 1, Figure 5). Significant heterogeneity was detected $\left(\mathrm{I}^{2}=98 \%, P<0.0001\right)$ but no single study was identified as the main contributor to the heterogeneity observed.

Publication bias

Assessment of publication bias through visual analysis of funnel plots showed no evidence of asymmetrical distribution for the ten antioxidants considered (Supplemental Figures 2.2.1-10).

\section{DISCUSSION}

These meta-analyses considered 52 studies to compare the levels of ten plasma antioxidants in individuals with $\mathrm{AD}$ to those of cognitively intact controls. Our findings are consistent with previous meta-analyses, which pooled data on five of the nine exogenous antioxidants included in our study $[9,10]$. We found significantly lower plasma levels of $\alpha$-carotene, $\beta$-carotene,lycopene, lutein, vitamins $\mathrm{A}, \mathrm{C}$ and $\mathrm{E}$ and uric acid among individuals with $\mathrm{AD}$. To our knowledge, we present the first meta-analysis to combine evidence comparing plasma levels of four less wellknown carotenoids to include lycopene, a member of the carotene subclass which we found to be significantly reduced in the plasma of individuals with $\mathrm{AD}$ compared with cognitively intact controls. Secondly, we present pooled data on three xanthophylls, a subclass which was not included in previous meta-analyses in this area of research. Our pooled analysis found lutein to be significantly reduced in $\mathrm{AD}$ while zeaxanthin and $\beta$-cryptoxanthin, despite showing decreased levels in $\mathrm{AD}$ versus controls, failed to reach the established significance threshold.

The importance of antioxidative vitamins in $\mathrm{AD}$ is predominantly due to their biological roles in maintaining neuronal integrity and preventing cell loss, nevertheless the findings previously 
reported have not always been consistent $[9,10]$. When meta-analyzed, concentrations of each vitamin were significantly lower in $\mathrm{AD}$, with vitamin $\mathrm{E}$ levels particularly important, given its contribution to total antioxidant defenses as the most potent radical-scavenging lipophilic antioxidant.

Uric acid, an endogenous antioxidant and the main end product of purine metabolism, was chosen as a proxy measure given its strong correlation with TAC [64]. Uric acid combats oxidative stress through multiple mechanisms including elimination of reactive oxygen and nitrogen species as well as chelation of iron, accounting for almost half of TAC. Our meta-analysis identified a negative correlation between plasma uric acid levels and $\mathrm{AD}$, similar to the dietary antioxidants considered. Uric acid levels were significantly lower in AD patients, even following sensitivity analysis, suggesting the findings of the meta-analysis were reliable.

We found no significant difference in serum levels of two of the three xanthophylls considered but all members of both dietary antioxidant subclasses, carotenes and vitamins, were significantly reduced in AD. Our results suggest significantly reduced levels of dietary antioxidants that is not limited to the pro-vitamin A carotenoids ( $\beta$-cryptoxanthin, $\alpha$-carotene and $\beta$-carotene) but rather to their subclasses (xanthophylls, carotenes and vitamins), which may be of clinical significance. Differential depletion among dietary antioxidants should be considered with respect to their properties such as water solubility, serum prevalence, and anti-oxidative capacity. The most prevalent exogenous antioxidants in plasma, which correlate with those most commonly found in the diet, are carotenes - lycopene and $\beta$-carotene. [65]. Under conditions of oxidative stress, carotenes, as a lipophilic carotenoid subclass, elute first and are preferentially 
depleted. In contrast, the xanthophylls, which are more hydrophilic in nature, are more likely to deplete at a slower rate in plasma and tend to be retained longer $[5,66]$.

The dominant carotenoids, lutein and zeaxanthin, exist at a 500 fold higher concentration in the brain and macula region of the eye than in the plasma, providing neuroprotection through multiple mechanisms, including control of free-radical mediated damage. In AD, the oxidative stressed brain may preferentially utilize xanthophylls from the large neural tissue reserves in the process of preserving homeostasis in the peripheral circulation until the latter stages of the disease. This theory is supported by findings from the EVA study, which found a reduction in plasma zeaxanthin levels among participants of the lowest cognitive functioning group as their ability to counteract the oxidative attack deteriorates [67]. Others studies have found no significant difference in plasma lutein levels between mild and moderate AD populations [18].

Sensitivity analyses identified significant heterogeneity among the xanthophyll class with Wang and colleagues reporting non-significant elevation of plasma lutein, zeaxanthin and $\beta$ cryptoxanthin in mild and moderate $\mathrm{AD}$ patient groups but significantly lower levels in severe $\mathrm{AD}$ as defence mechanisms fail [22]. In the sensitivity analyses, the pooled effects showed significantly reduced levels of serum lutein, zeaxanthin and $\beta$-cryptoxanthin in individuals with AD following exclusion of this study.

Collectively, our results suggest alterations in dietary antioxidant status are relevant within the sequelae of the disease. The lower plasma levels within the carotene and vitamin subclasses suggest patients with $\mathrm{AD}$ have impaired systemic availability of these exogenous antioxidants. Regardless of whether the antioxidant deficit was established from psychological factors resulting in micronutrient undernutrition or pathophysiological factors causing a pro-oxidative imbalance, 
AD patients can be characterized as having disease-specific dietary requirements. The outcomes of our study highlight the importance of considering strategies to explore the potential utility of nutrition in $\mathrm{AD}$ prevention in order to compensate for the lower plasma antioxidant availability such as supplement use or increased intake of antioxidant-rich foods.

Heterogeneity among studies included remains a considerable limitation of this meta-analysis approach. We attempted to minimize heterogeneity by limiting the meta-analyses to case-control study designs and, where supplements were used amongst subjects in certain studies, we extracted the data for non-supplement users to best represent habitual plasma levels.

There were a number of further limitations of the data used within the meta-analyses. First, variations in the analysis methods used to quantify plasma antioxidant status in subjects may have had a significant influence on the heterogeneity detected. Second, the small sample size in the majority of studies remains a challenge through insufficient statistical power. Several included studies failed to report data as parametric summary statistics. The transformations performed in our analysis were based on the assumption of normal distribution of data, which may not have been valid across all studies. Thirdly, variation in the characterization and classification of cognitively intact control samples may exist across studies and we made no attempt to censure this. A further methodological limitation concerns the risk of biases associated with case-control study design. Our results are susceptible to reverse causation, as it is not possible to affirm whether the low levels of carotenoids and vitamins preceded or were the consequence of AD. Previously, hypotheses in support of lower levels of plasma antioxidant as a consequence of $\mathrm{AD}$ focused on a) diminished dietary intake of antioxidant-rich foods as a result of AD-related cognitive decline and b) the eventual exhaustion of antioxidant defenses due to increasing oxidative stress in severe 
AD. Alternatively, older persons with AD may be at particular risk of poor nutrition for other reasons, including financial insecurity, medication use, poor dentition and decreased sense of taste and smell [68]. Furthermore, analyses were not performed separately for studies that used serum and plasma. $\mathrm{Yu}$ and colleagues reported a high correlation between plasma and serum measurements of metabolites overall (mean $\mathrm{r}^{2}=0.81$ ), although individual metabolite correlations between serum and plasma ranged from 0.01 to 0.96 [69]. Moreover, they reported higher sensitivity in biomarker detection from serum compared to plasma samples, although this had little bearing on their overall conclusions.

Differential control of potential confounders across included studies is a further limitation to our study. Only a proportion of studies controlled for factors such as total energy intake, supplement use and smoking. The inconsistent matching of patients with controls, even for age and sex, could in part confound our findings, given one third (17/52) of studies included did not achieve age and sex matching. We found that pooled effects of lutein, zeaxanthin and beta-cryptoxanthin reached significance $(\mathrm{p}<0.05)$ in a subgroup meta-analysis limited to studies with age and sex matching (data not shown). Furthermore, as one study was based on an all-female population [19], caution should be exercised given recent findings suggesting women have superior plasmatic antioxidant defenses [70]. It has been postulated that this sex discordance may be due to a combination of hormonal and lifestyle factors with a higher dietary intake of antioxidant-rich foods observed among women [71-73]. The failure of the majority of studies to provide data on antioxidant levels differentiated by gender, make such analyses extremely challenging. As increasing age and female gender are established risk factors of $\mathrm{AD}$, we cannot exclude the possibility that dissimilar participant demographics may have confounded the apparent association between lower serum 
antioxidant levels and AD. Finally, flavonoids were the only subclass of dietary antioxidant unaccounted in our study, as there was insufficient evidence from case-control studies to conduct a meta-analysis.

Our data suggests that alterations in serum antioxidant levels may form part of the pathophysiological processes of $\mathrm{AD}$ and highlights the specific antioxidant requirements of these patients. This paper provides support for large, adequately powered, longitudinal case-control studies that should be conducted with better matching while examining differences between disease stages so that the transition point at which these changes occur in serum antioxidant levels can be determined. Such information could then inform the development of adequately powered RCTs.

Moreover, the correction of the antioxidant imbalance via supplementation or dietary modification offers an important potential opportunity to modify AD risk or slow progression at various points in the disease spectrum. The introduction of feasible nutritional interventions with few side effects in $\mathrm{AD}$ prevention is of great importance in an emergent field of major public health concern. It is critical that future research acknowledges the limitations of past trials and consider the evidencebased approach to study design for nutritional interventions, whether via diet or supplements, including consideration of dose, timing and specificity of antioxidant targeting. As such, future research focussing on trials designed to evaluate this hypothesis would advance our understanding of compromised antioxidant status in $\mathrm{AD}$.

In conclusion, our data confirms that patients with $\mathrm{AD}$ have a systemic antioxidant deficiency with significantly lower plasma levels found in eight of the ten antioxidants investigated. Although two antioxidants within the xanthophyll subclass failed to reach statistical significance, a strong trend 
towards decreased levels in $\mathrm{AD}$ was observed. It is critical that future studies consider larger sample sizes and potential confounding to limit the impact of heterogeneity. Given these caveats, the evidence should be considered with caution to inform the design of future interventions in AD prevention. 


\section{REFERENCES}

[1] Prince M, Wimo A, Guerchet M, Gemma-Claire A, Wu Y-T, Prina M (2015) World Alzheimer Report 2015: The Global Impact of Dementia - An analysis of prevalence, incidence, cost and trends. Alzheimer's Dis. Int. 84.

[2] M. Niedowicz D, T. Nelson P, Paul Murphy M (2011) Alzheimer's Disease: Pathological Mechanisms and Recent Insights. Curr. Neuropharmacol. 9, 674-684.

[3] Prince M, Albanese E, Guerchet M, Prina, M (2014) World Alzheimer's Report 2014: Dementia and Risk Reduction: An Analysis of Protective and Modifiable Factors. Alzheimer's Dis. Int.

[4] Sopher BL, Fukuchi K, Kavanagh TJ, Furlong CE, Martin GM (1996) Neurodegenerative mechanisms in Alzheimer disease. A role for oxidative damage in amyloid beta protein precursor-mediated cell death. Mol.Chem.Neuropathol. 29, 153-168.

[5] Polidori MC, Stahl W, Eichler O, Niestroj I, Sies H (2001) Profiles of antioxidants in human plasma. Free Radic. Biol. Med. 30, 456-462.

[6] Lobo V, Patil A, Phatak A, Chandra N (2010) Free radicals, antioxidants and functional foods: Impact on human health. Pharmacogn. Rev. 4, 118-26.

[7] Broekmans WMR, Klö Pping-Ketelaars IAA, Schuurman CRWC, Verhagen H, Van Den Berg H, Kok FJ, Van Poppel G (2000) Human Nutrition and Metabolism Fruits and Vegetables Increase Plasma Carotenoids and Vitamins and Decrease Homocysteine in Humans 1. J. Nutr 130, 1578-1583.

[8] Morris MC, Evans DA, Tangney CC, Bienias JL, Wilson RS (2006) Associations of vegetable and fruit consumption with age-related cognitive change. Neurology 67, 1370-1376.

[9] Schrag M, Mueller C, Zabel M, Crofton A, Kirsch WM, Ghribi O, Squitti R, Perry G (2013) Oxidative stress in blood in Alzheimer's disease and mild cognitive impairment: A meta-analysis. Neurobiol. Dis. 59, 100110 .

[10] Lopes da Silva S, Vellas B, Elemans S, Luchsinger J, Kamphuis P, Yaffe K, Sijben J, Groenendijk M, Stijnen T (2014) Plasma nutrient status of patients with Alzheimer's disease: Systematic review and meta-analysis. Alzheimer's Dement. 10, 485-502.

[11] Dysken MW, Sano M, Asthana S, Vertrees JE, Pallaki M, Llorente M, Love S, Schellenberg GD, McCarten JR, Malphurs J, Prieto S, Chen P, Loreck DJ, Trapp G, Bakshi RS, Mintzer JE, Heidebrink JL, Vidal-Cardona A, Arroyo LM, Cruz AR, Zachariah S, Kowall NW, Chopra MP, Craft S, Thielke S, Turvey CL, Woodman C, Monnell KA, Gordon K, Tomaska J, Segal Y, Peduzzi PN, Guarino PD (2014) Effect of vitamin E and memantine on functional decline in Alzheimer disease: the TEAM-AD VA cooperative randomized trial. Jama 311, 33-44.

[12] Petersen RC, Thomas RG, Grundman M, Bennett D, Doody R, Ferris S, Galasko D, Jin S, Kaye J, Levey A, Pfeiffer E, Sano M, van Dyck CH, Thal LJ (2005) Vitamin E and donepezil for the treatment of mild cognitive impairment. N. Engl. J. Med. 352, 2379-2388.

[13] Liberati A, Altman DG, Tetzlaff J, Mulrow C, Gøtzsche PC, Ioannidis JPA, Clarke M, Devereaux PJ, Kleijnen J, Moher D (2009) The PRISMA statement for reporting systematic reviews and meta-analyses of studies that evaluate health care interventions: explanation and elaboration. In Journal of clinical epidemiology, pp. e1-34.

[14] DerSimonian R, Laird N (1986) Meta-analysis in clinical trials. Control. Clin. Trials 7, 177-88.

[15] Foy CJ, Passmore AP, Vahidassr MD, Young IS, Lawson JT (1999) Plasma chain-breaking antioxidants in Alzheimer's disease, vascular dementia and Parkinson's disease. QJM-MONTHLY J. Assoc. PHYSICIANS 92, 39-45.

[16] Jimenez-Jimenez FJ, Molina JA, de Bustos F, Orti-Pareja M, Benito-Leon J, Tallon-Barranco A, Gasalla T, Porta J, Arenas J (1999) Serum levels of beta-carotene, alpha-carotene and vitamin A in patients with Alzheimer's disease. Eur. J. Neurol. 6, 495-497.

[17] Schippling S, Kontush A, Arlt S, Buhmann C, Sturenburg HJ, Mann U, Muller-Thomsen T, Beisiegel U (2000) Increased lipoprotein oxidation in Alzheimer's disease. Free Radic. Biol. Med. 28, 351-360. 
[18] Mecocci P, Polidori MC, Cherubini A, Ingegni T, Mattioli P, Catani M, Rinaldi P, Cecchetti R, Stahl W, Senin U, Beal MF (2002) Lymphocyte oxidative DNA damage and plasma antioxidants in Alzheimer disease. Arch. Neurol. 59, 794-798.

[19] Polidori MC, Mecocci P (2002) Plasma susceptibility to free radical-induced antioxidant consumption and lipid peroxidation is increased in very old subjects with Alzheimer disease. J. ALZHEIMERS Dis. 4, 517522.

[20] Rinaldi P, Polidori MC, Metastasio A, Mariani E, Mattioli R, Cherubini A, Catani M, Cecchetti R, Senin U, Mecocci P (2003) Plasma antioxidants are similarly depleted in mild cognitive impairment and in Alzheimer's disease. Neurobiol. Aging 24, 915-919.

[21] Quinn J, Suh J, Moore MM, Kaye J, Frei B (2003) Antioxidants in Alzheimer's disease-vitamin C delivery to a demanding brain. J. Alzheimers. Dis. 5, 309-313.

[22] Wang W, Shinto L, Connor WE, Quinn JF (2008) Nutritional biomarkers in Alzheimer's disease: The association between carotenoids, n-3 fatty acids, and dementia severity. J. ALZHEIMERS Dis. 13, 31-38.

[23] Nolan JM, Loskutova E, Howard AN, Moran R, Mulcahy R, Stack J, et al. Macular pigment, visual function, and macular disease among subjects with Alzheimer's disease: An exploratory study. J Alzheimers Dis. 2014; 42, 1191-1202

[24] Zaman Z, Roche S, Fielden P, Frost PG, Niriella DC, Cayley AC (1992) Plasma concentrations of vitamins $A$ and $E$ and carotenoids in Alzheimer's disease. Age Ageing 21, 91-94.

[25] Sinclair AJ, Bayer AJ, Johnston J, Warner C, Maxwell SRJ (1998) Altered plasma antioxidant status in subjects with Alzheimer's disease and vascular dementia. Int. J. Geriatr. Psychiatry 13, 840-845.

[26] Mangialasche F, Xu W, Kivipelto M, Costanzi E, Ercolani S, Pigliautile M, Cecchetti R, Baglioni M, Simmons A, Soininen H, Tsolaki M, Kloszewska I, Vellas B, Lovestone S, Mecocci P (2012) Tocopherols and tocotrienols plasma levels are associated with cognitive impairment. Neurobiol. Aging 33, 2282-2290.

[27] von Arnim CAF, Herbolsheimer F, Nikolaus T, Peter R, Biesalski HK, Ludolph AC, Riepe M, Nagel G, Grp AUS (2012) Dietary Antioxidants and Dementia in a Population-Based Case-Control Study among Older People in South Germany. J. ALZHEIMERS Dis. 31, 717-724.

[28] Giavarotti L, Simon KA, Azzalis LA, Fonseca FLA, Lima AF, Freitas MC V, Brunialti MKC, Salomao R, Moscardi AAVS, Montano MBMM, Ramos LR, Junqueira VBC (2013) Mild Systemic Oxidative Stress in the Subclinical Stage of Alzheimer's Disease. Oxid. Med. Cell. Longev.

[29] Jeandel C, Nicolas MB, Dubois F, Nabet-Belleville F, Penin F, Cuny G (1989) Lipid peroxidation and free radical scavengers in Alzheimer's disease. Gerontology 35, 275-282.

[30] Bourdel-Marchasson I, Delmas-Beauvieux MC, Peuchant E, Richard-Harston S, Decamps A, Reignier B, Emeriau JP, Rainfray M (2001) Antioxidant defences and oxidative stress markers in erythrocytes and plasma from normally nourished elderly Alzheimer patients. Age Ageing 30, 235-241.

[31] Glaso M, Nordbo G, Diep L, Bohmer T (2004) Reduced concentrations of several vitamins in normal weight patients with late-onset dementia of the Alzheimer type without vascular disease. J. Nutr. Health Aging 8, 407-413.

[32] Engelhart MJ, Ruitenberg A, Meijer J, Kiliaan A, van Swieten JC, Hofman A, Witteman JC, Breteler MM (2005) Plasma levels of antioxidants are not associated with Alzheimer's disease or cognitive decline. Dement. Geriatr. Cogn. Disord. 19, 134-139.

[33] Baldeiras I, Santana I, Proença MT, Garrucho MH, Pascoal R, Rodrigues A, Duro D, Oliveira CR (2008) Peripheral oxidative damage in mild cognitive impairment and mild Alzheimer's disease. J. Alzheimer's Dis. $15,117-128$.

[34] Olde Rikkert MGM, Verhey FR, Sijben JWC, Bouwman FH, Dautzenberg PLJ, Lansink M, Sipers WMW, Van Asselt DZB, Van Hees AMJ, Stevens M, Vellas B, Scheltens P (2014) Differences in nutritional status between very mild Alzheimer's disease patients and healthy controls. J. Alzheimer's Dis. 41, 261-271.

[35] Mangialasche F, Baglioni M, Cecchetti R, Kivipelto M, Ruggiero C, Piobbico D, Kussmaul L, Monastero R, Brancorsini S, Mecocci P (2015) Lymphocytic mitochondrial aconitase activity is reduced in Alzheimer's disease and mild cognitive impairment. J. Alzheimer's Dis. 44, 649-660.

[36] Agbayewa MO, Bruce VM, Siemens V (1992) Pyridoxine, ascorbic acid and thiamine in Alzheimer and comparison subjects. Can. J. Psychiatry. 37, 661-662. 
[37] Paraskevas GP, Kapaki E, Libitaki G, Zournas C, Segditsa I, Papageorgiou C (1997) Ascorbate in healthy subjects, amyotrophic lateral sclerosis and Alzheimer's disease. ACTA Neurol. Scand. 96, 88-90.

[38] Aejmelaeus R, Ketela TM, Pirttila T, Hervonen A, Alho H (1997) Unidentified antioxidant defences of human plasma in immobilized patients: a possible relation to basic metabolic rate. Free Radic. Res. 26, 335341.

[39] Rivière S, Birlouez-Aragon I, Nourhashémi F, Vellas B (1998) Low plasma vitamin C in Alzheimer patients despite an adequate diet. Int. J. Geriatr. Psychiatry 13, 749-754.

[40] Haines A, Iliffe S, Morgan P, Dormandy T, Wood B (1991) Serum aluminium and zinc and other variables in patients with and without cognitive impairment in the community. Clin. Chim. Acta 198, 261-266.

[41] Ahlskog JE, Uitti RJ, Low PA, Tyce GM, Nickander KK, Petersen RC, Kokmen E (1995) No evidence for systemic oxidant stress in Parkinson's or Alzheimer's disease. Mov. Disord. 10, $566-573$.

[42] Fernandes MA, Proenca MT, Nogueira AJ, Grazina MM, Oliveira LM, Fernandes AI, Santiago B, Santana I, Oliveira CR (1999) Influence of apolipoprotein E genotype on blood redox status of Alzheimer's disease patients. Int. J. Mol. Med. 4, 179-186.

[43] Feillet-Coudray C, Tourtauchaux R, Niculescu M, Rock E, Tauveron I, Alexandre-Gouabau M-C, Rayssiguier Y, Jalenques I, Mazur A (1999) Plasma levels of 8-epiPGF2 $\alpha$, an in vivo marker of oxidative stress, are not affected by aging or Alzheimer's disease. Free Radic. Biol. Med. 27, 463-469.

[44] Ryglewicz D, Rodo M, Kunicki PK, Bednarska-Makaruk M, Graban A, Lojkowska W, Wehr H (2002) Plasma antioxidant activity and vascular dementia. J. Neurol. Sci. 203-204, 195-197.

[45] Battino M, Bompadre S, Leone L, Devecchi E, Degiuli A, D’Agostino F, Cambie G, D’Agostino M, Faggi L, Colturani G, Gorini A, Villa RF (2003) Coenzyme Q, Vitamin E and Apo-E alleles in Alzheimer Disease. Biofactors 18, 277-281.

[46] Liebler DC, Burr JA, Philips L, Ham AJL (1996) Gas Chromatography-Mass Spectrometry Analysis of Vitamin E and Its Oxidation Products. Anal. Biochem. 236, 27-34.

[47] Ciabattoni G, Porreca E, Di Febbo C, Di Iorio A, Paganelli R, Bucciarelli T, Pescara L, Del Re L, Giusti C, Falco A, Sau A, Patrono C, Davi G (2007) Determinants of platelet activation in Alzheimer's disease. Neurobiol. Aging 28, 336-342.

[48] El-Sayed DA, Salah H, El-Abyary MM, Zaitoun AM, Gaballah A (2009) Alzheimer's disease: Serum biological markers in relation to disease severity. Egypt. J. Neurol. Psychiatry Neurosurg. 46, 177-183.

[49] Iuliano L, Monticolo R, Straface G, Spoletini I, Gianni W, Caltagirone C, Bossu P, Spalletta G (2010) Vitamin $\mathrm{E}$ and enzymatic/oxidative stress-driven oxysterols in amnestic mild cognitive impairment subtypes and Alzheimer's disease. J. Alzheimers. Dis. 21, 1383-1392.

[50] Cristalli DO, Arnal N, Marra FA, De Alaniz MJT, Marra CA (2012) Peripheral markers in neurodegenerative patients and their first-degree relatives. J. Neurol. Sci. 314, 48-56.

[51] Mangialasche F, Westman E, Kivipelto M, Muehlboeck J-S, Cecchetti R, Baglioni M, Tarducci R, Gobbi G, Floridi P, Soininen H, Kloszewska I, Tsolaki M, Vellas B, Spenger C, Lovestone S, Wahlund L-O, Simmons A, Mecocci P (2013) Classification and prediction of clinical diagnosis of Alzheimer's disease based on MRI and plasma measures of alpha-/gamma-tocotrienols and gamma-tocopherol. J. Intern. Med. 273, 602621.

[52] Maesaka JK, Wolf-Klein G, Piccione JM, Ma CM (1993) Hypouricemia, abnormal renal tubular urate transport, and plasma natriuretic factor(s) in patients with Alzheimer's disease. J. Am. Geriatr. Soc. 41, 501506.

[53] Carantoni M, Zuliani G, Munari MR, D’Elia K, Palmieri E, Fellin R (2000) Alzheimer disease and vascular dementia: Relationships with fasting glucose and insulin levels. Dement. Geriatr. Cogn. Disord. 11, 176180.

[54] Zafrilla P, Mulero J, Xandri JM, Santo E, Caravaca G, Morillas JM (2006) Oxidative stress in Alzheimer patients in different stages of the disease. Curr. Med. Chem. 13, 1075-1083.

[55] Kim T-S, Pae C-U, Yoon S-J, Jang W-Y, Lee NJ, Kim J-J, Lee S-J, Lee C, Paik I-H, Lee C-U (2006) Decreased plasma antioxidants in patients with Alzheimer's disease. Int. J. Geriatr. Psychiatry 21, 344-348.

[56] Cascalheira JF, João SS, Pinhanços SS, Castro R, Palmeira M, Almeida S, Faria MC, Domingues FC (2009) Serum homocysteine: Interplay with other circulating and genetic factors in association to Alzheimer's type dementia. Clin. Biochem. 42, 783-790. 
[57] Cankurtaran M, Yesil Y, Kuyumcu ME, Oztürk ZA, Yavuz BB, Halil M, Ulger Z, Cankurtaran ES, Arioğul S (2013) Altered levels of homocysteine and serum natural antioxidants links oxidative damage to Alzheimer's disease. J. Alzheimer's Dis. 33, 1051-1058.

[58] Can M, Varlibas F, Guven B, Akhan O, Yuksel GA (2013) Ischemia modified albumin and plasma oxidative stress markers in Alzheimer's disease. Eur. Neurol. 69, 377-380.

[59] Cervellati C, Romani A, Seripa D, Cremonini E, Bosi C, Magon S, Passaro A, Bergamini CM, Pilotto A, Zuliani G (2014) Oxidative balance, homocysteine, and uric acid levels in older patients with Late Onset Alzheimer's Disease or Vascular Dementia. J. Neurol. Sci. 337, 156-161.

[60] Cervellati C, Cremonini E, Bosi C, Magon S, Zurlo A, Bergamini CM, Zuliani G (2013) Systemic oxidative stress in older patients with mild cognitive impairment or late onset Alzheimer's disease. Curr. Alzheimer Res. 10, 365-372.

[61] Nazef K, Khelil M, Chelouti H, Kacimi G, Bendini M, Tazir M, Belarbi S, El Hadi Cherifi M, Djerdjouri B (2014) Hyperhomocysteinemia Is a Risk Factor for Alzheimer's Disease in an Algerian Population. Arch. Med. Res. 45, 247-250.

[62] Al-Khateeb E, Althaher A, Al-Khateeb M, Al-Musawi H, Azzouqah O, Al-Shweiki S, Shafagoj Y (2015) Relation between uric acid and Alzheimer's disease in elderly Jordanians. J. Alzheimer's Dis. 44, 859-865.

[63] Hatanaka H, Hanyu H, Fukasawa R, Hirao K, Shimizu S, Kanetaka H, Iwamoto T (2015) Differences in peripheral oxidative stress markers in Alzheimer's disease, vascular dementia and mixed dementia patients. Geriatr. Gerontol. Int. 15, 53-58.

[64] Sautin YY, Johnson RJ (2008) Uric acid: the oxidant-antioxidant paradox. Nucleosides. Nucleotides Nucleic Acids 27, 608-19.

[65] Polidori MC, Stahl W, Eichler O, Niestroj I, Sies H (2001) Profiles of antioxidants in human plasma. Free Radic. Biol. Med. 30, 456-462.

[66] Widomska J, Zareba M, Subczynski WK (2016) Can xanthophyll-membrane interactions explain their selective presence in the retina and brain? Foods 5, 1-25.

[67] Akbaraly NT, Faure H, Gourlet V, Favier A, Berr C (2007) Plasma carotenoid levels and cognitive performance in an elderly population: results of the EVA Study. J. Gerontol. A. Biol. Sci. Med. Sci. 62, 30816.

[68] Saka B, Kaya O, Ozturk GB, Erten N, Karan MA (2010) Malnutrition in the elderly and its relationship with other geriatric syndromes. Clin. Nutr. 29, 745-748.

[69] Yu Z, Kastenmüller G, He Y, Belcredi P, Möller G, Prehn C, Mendes J, Wahl S, Roemisch-Margl W, Ceglarek U, Polonikov A, Dahmen N, Prokisch H, Xie L, Li Y, Wichmann H-E, Peters A, Kronenberg F, Suhre K, Adamski J, Illig T, Wang-Sattler R (2011) Differences between human plasma and serum metabolite profiles. PLoS One 6, e21230.

[70] Liu H, Harrell LE, Shenvi S, Hagen T, Liu RM (2005) Gender differences in glutathione metabolism in Alzheimer's disease. J. Neurosci. Res. 79, 861-867.

[71] De Waart FG, Schouten EG, Stalenhoef AF, Kok FJ (2001) Serum carotenoids, alpha-tocopherol and mortality risk in a prospective study among Dutch elderly. Int. J. Epidemiol. 30, 136-143.

[72] Olmedilla B, Granado F, Southon S, Wright AJ a, Blanco I, Gil-Martinez E, van den Berg H, Thurnham D, Corridan B, Chopra M, Hininger I (2002) A European multicentre, placebo-controlled supplementation study with alpha-tocopherol, carotene-rich palm oil, lutein or lycopene: analysis of serum responses. Clin. Sci. (Lond). 102, 447-56.

[73] Wallstrom P, Wirfalt E, Lahmann PH, Gullberg B, Janzon L, Berglund G (2001) Serum concentrations of beta-carotene and alpha-tocopherol are associated with diet, smoking, and general and central adiposity. Am. J. Clin. Nutr. 73, 777-785. 


\begin{tabular}{lccc}
\hline & & Total N AD / & PMD (95\% CI) \\
Antioxidant & Studies Included & $327 / 269$ & $-0.03[-0.05,-0.01]$ \\
\hline Alpha-carotene & 8 & $701 / 633$ & $-0.11[-0.17,-0.04]$ \\
Beta-carotene & 13 & $424 / 319$ & $-0.15[-0.27,-0.02]$ \\
Lycopene & 7 & $174 / 145$ & $-0.13[-0.28,0.01]$ \\
Beta-cryptoxanthin & 4 & $210 / 178$ & $-0.13[-0.23,-0.03]$ \\
Lutein & 5 & $210 / 178$ & $-0.03[-0.07,0.00]$ \\
Zeaxanthin & 5 & $752 / 1104$ & $-0.78[-1.18,-0.39]$ \\
Vitamin A & 15 & $623 / 491$ & $-12.6[-17.7,-7.40]$ \\
Vitamin C & 16 & $1554 / 1872$ & $-5.26[-6.64,-3.89]$ \\
Vitamin E & 31 & $1110 / 2384$ & $-27.4[-49.8,-5.00]$ \\
Uric Acid & 21 & & \\
\hline
\end{tabular}

Table 1. Summary measures for the meta-analyzed data for the ten antioxidants investigated. Abbreviations: AD, Alzheimer's disease; CI, confidence interval; PMD, Pooled mean difference 


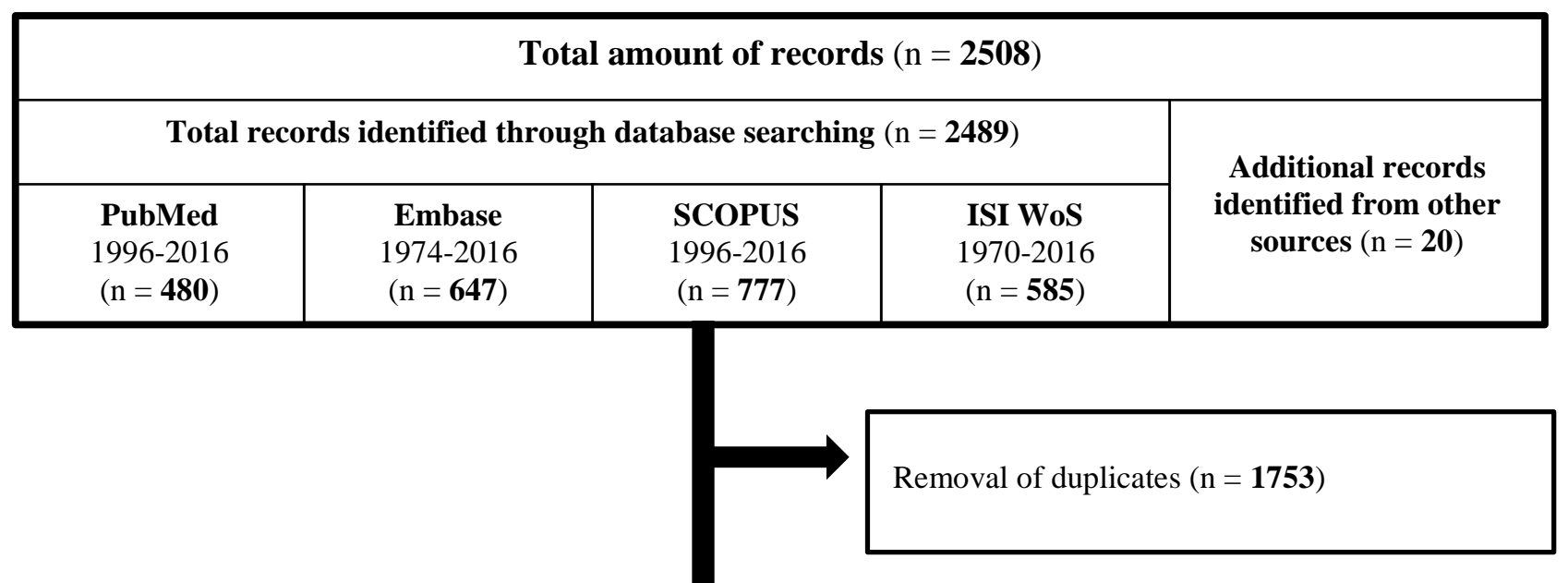

Titles and abstracts screened $(\mathrm{n}=\mathbf{7 5 5})$

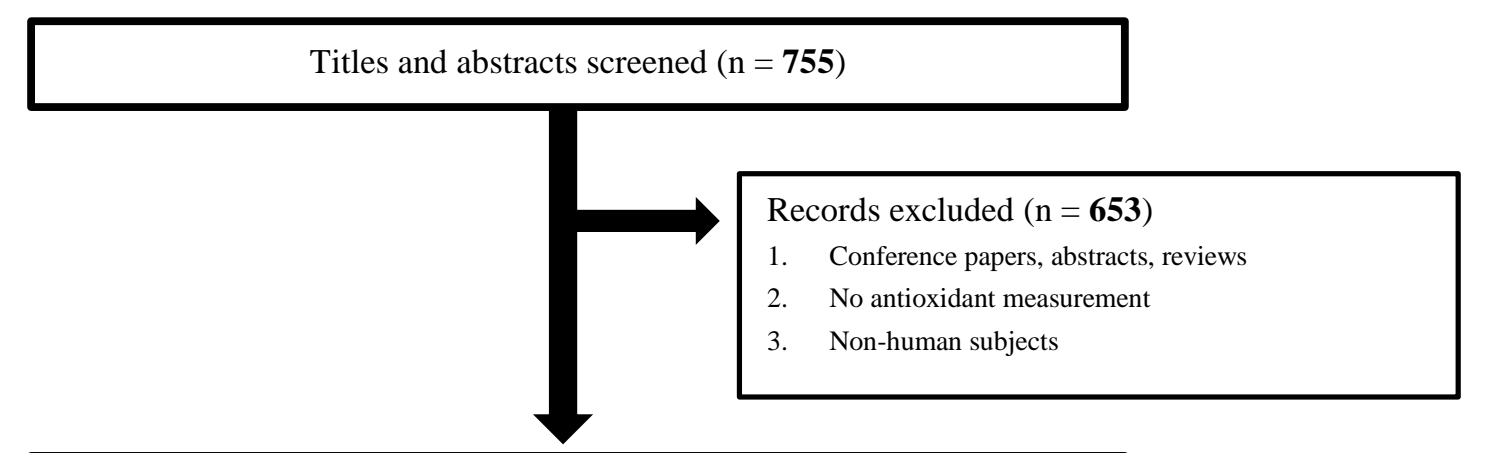

Full text articles assessed for eligibility $(\mathrm{n}=\mathbf{1 0 2})$
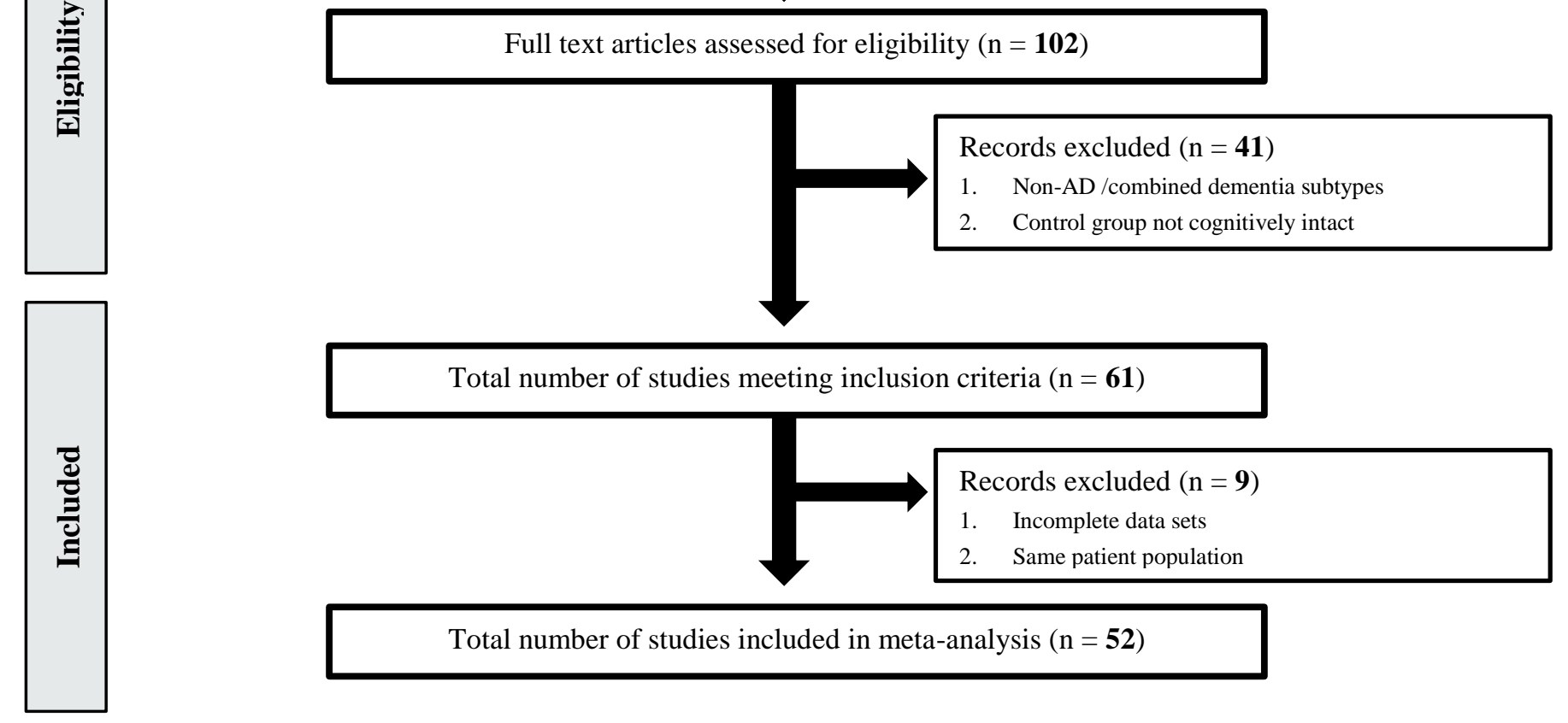

Total number of studies included in meta-analysis $(n=\mathbf{5 2})$

Figure 1. PRISMA diagram of breakdown of publication selection

Schematic detailing the search and sub-selection of case-control studies in the metaanalysis. Studies were published from 1989 to September 2016.

Abbreviations: WoS, Web of Science, AD, Alzheimer's disease. 


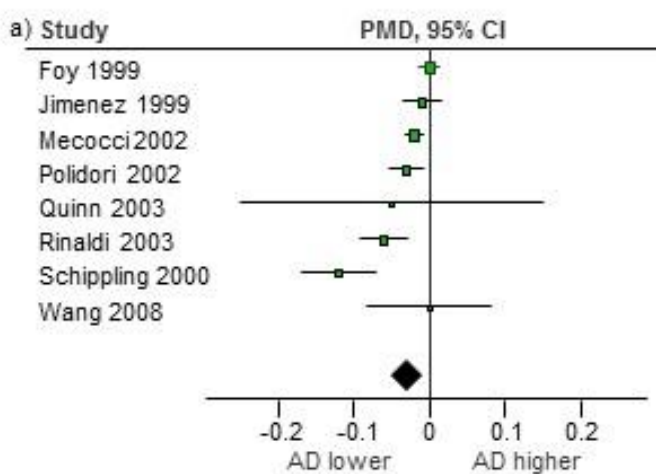

Pooled Effect $(95 \% \mathrm{Cl})-0.03(-0.05,-0.01)(P=0.003)$ Heterogeneity: $P<0.0001 ; F^{2}=78 \%$

$$
\begin{aligned}
& \text { b) Stu } \\
& \hline \text { Zam } \\
& \text { Sinc } \\
& \text { Foy } \\
& \text { Jime } \\
& \text { Schip } \\
& \text { Polid } \\
& \text { Mec } \\
& \text { Quin } \\
& \text { Rina } \\
& \text { Wan } \\
& \text { von } \\
& \text { Man }
\end{aligned}
$$

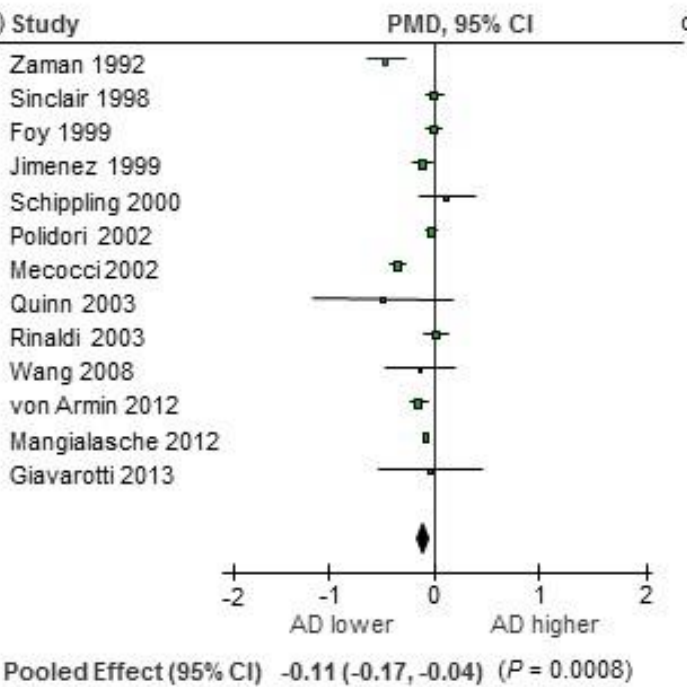

Pooled Effect $(95 \% \mathrm{Cl})-0.11(-0.17,-0.04) \quad(P=0.0008)$ Heterogeneity: $P<0.00001 ; 1^{2}=86 \%$

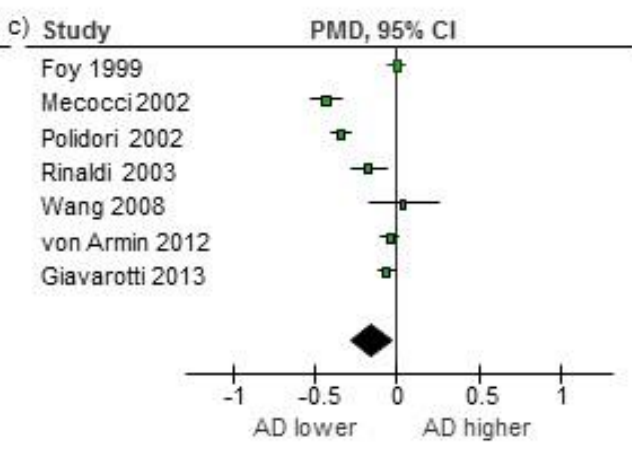

Pooled Effect $(95 \% \mathrm{Cl})-0.15(-0.27,-0.02)(P=0.02)$ Heterogeneity: $(P<0.00001) ; 1^{2}=95 \%$

Figure 2. Pooled mean differences (PMDs) in plasma levels ( $\mu$ moles/liter) of three carotenes between AD patients and cognitively-intact controls (random effects model), 1992-2013.

Left to right; a) alpha-carotene, b) beta-carotene, c) lycopene.

The size of the squares correspond to the study-specific statistical weight from each case-control study, and the diamonds indicate the pooled weighted mean differences with corresponding $95 \%$ confidence intervals. Horizontal lines, $95 \%$ confidence intervals (Cls).

Abbreviations: $\mathrm{Cl}$, confidence interval; $\mathrm{PMD}$, pooled mean difference. 


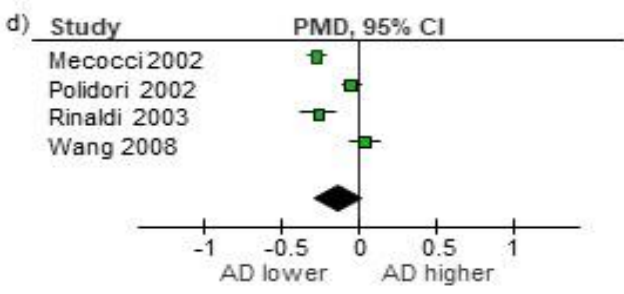

Total $(95 \% \mathrm{Cl})-0.13[-0.28,0.01](\mathrm{P}=0.08)$ Heterogeneity: $(P<0.00001) ;{ }^{2}=93 \%$ e) Study

Polidori 2002
Mecocci2002

Mecocci 2002

Wang 2008

Nolan 2014

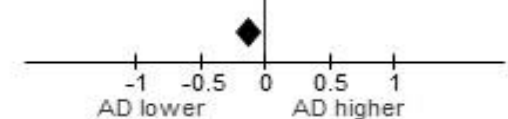

Total $(95 \% \mathrm{Cl})-0.13[-0.23,-0.03](\mathrm{P}=0.01)$

Heterogeneity: $(P<0.00001) ; I^{2}=88 \%$

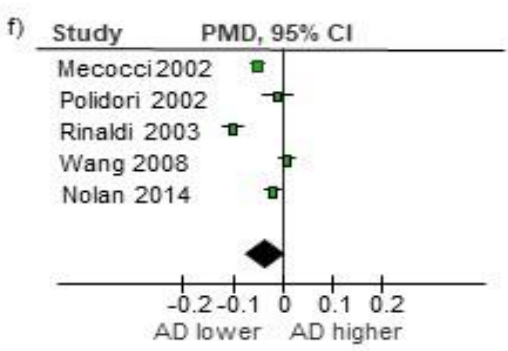

Total $(95 \% \mathrm{Cl})-0.03[-0.07-0.00](P=0.06)$

Heterogeneity: $(P<0.00001) ; I^{2}=94 \%$

Figure 3. Pooled mean differences (PMDs) in plasma levels of three xanthophylls between AD patients and cognitively-intact controls (random effects model), 2002-2014

Left to right; d) beta-cryptoxanthin, e) lutein, f) zeaxanthin.

The size of the squares correspond to the study-specific statistical weight from each case-control study, and the diamonds indicate the pooled weighted mean differences with corresponding $95 \%$ confidence intervals. Horizontal lines, $95 \%$ confidence intervals (Cls)

Abbreviations: $\mathrm{Cl}$, confidence interval; $\mathrm{PMD}$, pooled mean difference 


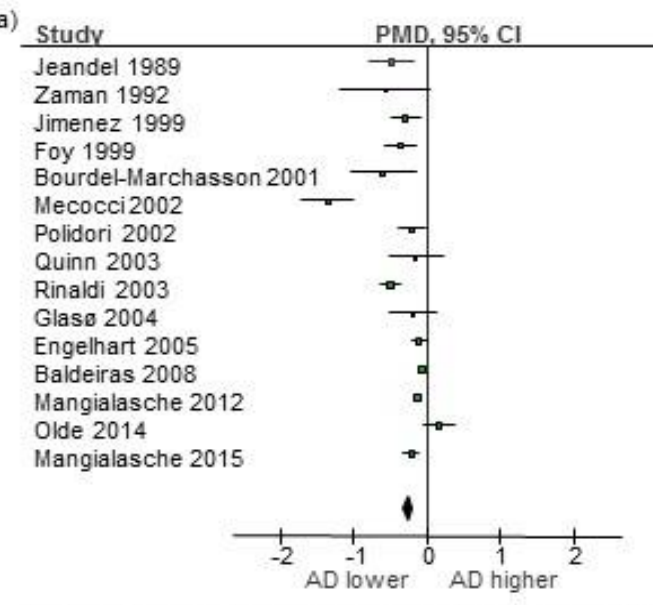

Pooled effect $(95 \% \mathrm{Cl})-0.26[-0.33,-0.18](\mathrm{P}<0.00001)$ Heterogeneity: $(P<0.00001) ; F^{2}=88 \%$

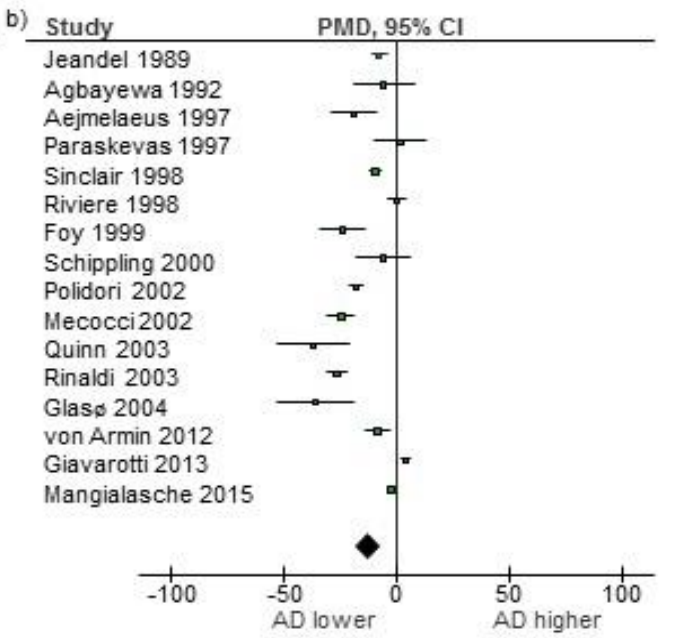

Pooled effect $(95 \% \mathrm{Cl})-12.58[-17.73,-7.43](\mathrm{P}<0.00001)$ Heterogeneity: $(P<0.00001) ; F^{2}=95 \%$

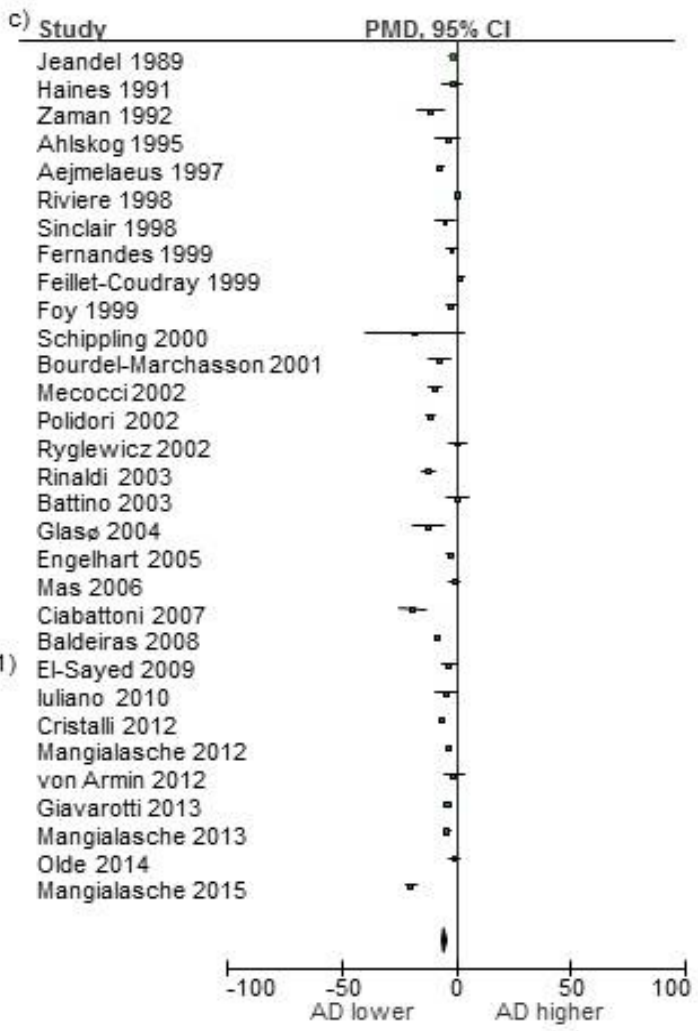

Pooled effect $(95 \% \mathrm{Cl})-5.26[-6.64,-3.89](\mathrm{P}<0.00001)$

Figure 4. Pooled mean differences (PMDs) in plasma levels ( $\mu$ moles/liter) of three vitamins between AD patients and cognitively-intact controls (random effects model), 1989-2015.

Left to right; a) Vitamnin A, b)Vitamin C, c) Vitamin E.

The size of the squares correspond to the study-specific statistical weight from each case-control study, and the diamonds indicate the pooled weighted mean differences with corresponding $95 \%$ confidence intervals. Horizontal lines, $95 \%$ confidence intervals (Cls)

Abbreviations: $\mathrm{Cl}$, confidence interval; $\mathrm{PMD}$, pooled mean difference. 


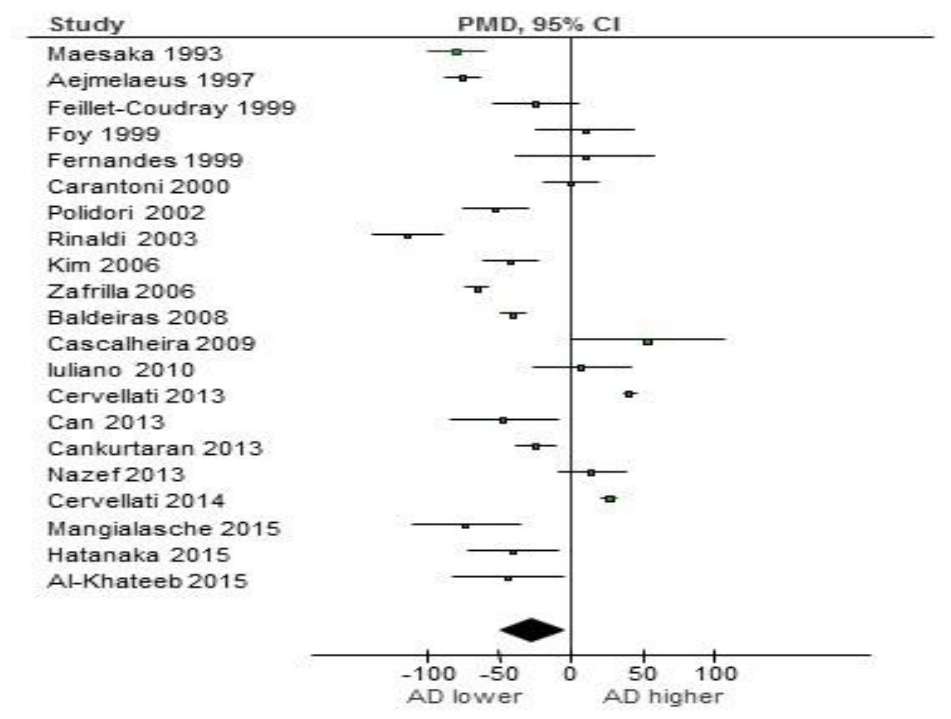

Pooled effect $(95 \% \mathrm{Cl})-27.37[-49.75,-5.00](P=0.02)$

Heterogeneity: $(P<0.00001) ; F^{2}=98 \%$

Figure 5. Pooled mean differences (PMDs) in plasma levels ( $\mu$ moles/liter) of Uric Acid between AD patients and cognitively-intact controls (random effects model), 1993-2015

The size of the squares correspond to the study-specific statistical weight from each case-control study, and the diamond indicates the pooled weighted mean differences with corresponding $95 \%$ confidence intervals. Horizontal lines, $95 \%$ confidence intervals (Cls).

Abbreviations: $\mathrm{Cl}$, confidence interval; $\mathrm{PMD}$, pooled mean difference 
